\title{
Da polêmica sobre a pós-modernidade aos 'desafios' lyotardianos à Filosofia da Educação
}

Pedro Angelo Pagni

Universidade Estadual Paulista

\section{Resumo}

As relações entre pós-modernidade e educação tem sido objeto de inúmeras pesquisas, bem como de certa polêmica no âmbito da Filosofia da Educação, a começar pela própria conceituação da pósmodernidade até chegar às posições filosóficas engendradas por ela. Em quase todas essas pesquisas e polêmicas, $A$ condição pósmoderna, de Jean François Lyotard, se configura como uma referência importante, porém raramente as obras subseqüentes a essa são mencionadas, deixando uma parte de seu legado filosófico de fora de tais discussões e, particularmente, de suas eventuais contribuições para a educação. Tendo em vista esse limiar dos estudos sobre o assunto, o presente artigo procura desenvolver uma interpretação acerca do pensamento lyotardiano, privilegiando a análise das obras subseqüentes ao seu livro mais polêmico, com o objetivo de situar o seu projeto filosófico para além de um marco da pósmodernidade e de discutir as suas contribuições à Filosofia da Educação na atualidade. Mediante tal interpretação, recupera-se um projeto filosófico que lança alguns 'desafios' à Filosofia da Educação referentes ao deslocamento de sua problemática epistemológica para a estética, nutrida por um pensamento capaz de elucidar a face complexa e obscura da educação, a sua sombra inumana, e o diferendo constitutivo do ensino, inapreensíveis pela linguagem e pela comunicação. Assim, esperamos que tal projeto possa ser compreendido não por aquilo que traz de polêmico à Filosofia da Educação, mas pelo que a desafia no tempo presente, como uma reescrita da modernidade.

\section{Palavras-chave}

Pós-modernidade - Filosofia da Educação - Diferendo - Jean François Lyotard. 


\title{
From the controversy of postmodernity to the Lyotardian "challenges" to the Philosophy of Education
}

\author{
Pedro Angelo Pagni \\ Universidade Estadual Paulista
}

\begin{abstract}
The relations between postmodernity and education have been the object of countless researches, and also of some controversy within the philosophy of education, starting with the very conception of postmodernity and extending to the philosophical positions it engenders. In almost every research and controversy, Jean-François Lyotard's The Postmodern Condition figures as an important reference, although his subsequent works are seldom mentioned, thereby leaving part of his philosophical legacy outside such discussions and, in particular, of his resulting contributions to education. In view of the current state of these studies, the present article seeks to develop an interpretation of the Lyotardian thought more strongly focused on the analysis of the works he published after his controversial book, with the purpose of placing his philosophical project beyond a landmark of postmodernity, and of discussing his contributions to the current philosophy of education. Such interpretation rescues a philosophical project that places before today's philosophy of education "challenges" concerning the move of its epistemological problems to the sphere of aesthetics, nurtured by a thinking capable of illuminating the complex and obscure face of education, its inhuman shadow, and the constitutive contention of teaching, inapprehensible by language and communication. We thus hope that such project can be understood not for the controversy it brings to the philosophy of education, but for the current challenges put to the latter as a rewriting of modernity.
\end{abstract}

\section{Keywords}

Postmodernity - Philosophy of education - Contention - JeanFrançois Lyotard.

Contact:

Pedro Angelo Pagni

Rua André Martins Parra, 171/25

17514-260-Marilia/SP

e-mail: pagni@flash.tv.br 
A pós-modernidade começou a se configurar como uma problemática filosófica entre o final da década de 1970 e meados de 1980 , ocupando o centro da polêmica protagonizada, inicialmente, por Jean François Lyotard e Jürgen Habermas e, depois, além destes, por Richard Rorty e Fredric Jameson - para mencionar apenas os principais expoentes. Essa polêmica começou a ser discutida no âmbito da Filosofia da Educação, no Brasil, no final dos anos 1980, circulando em alguns artigos e livros que abordaram as suas implicações para a Pedagogia ou para a Educação. Desde então, as relações entre pós-modernidade e educação têm sido objeto de pesquisas, bem como de certa polêmica no âmbito da Filosofia da Educação, a começar pela própria conceituação da pós-modernidade até chegar às posições filosóficas engendradas por ela. Os estudos que destacaram a posição de Habermas, na polêmica, o fizeram para discutir o papel das Ciências da Educação na modernidade (Markert, 1986) ou, então, compreender a educação na crise da modernidade (Göergen, 1996; 2001), apresentando a teoria do agir comunicativo (Medeiros, 1994; Gonçalves, 1999) ou o 'paradigma neomoderno' (Marques, 1992) como uma alternativa às implicações de tal crise no saber pedagógico ou no ensino. Assim também aconteceu com as produções acadêmicas em que essa polêmica apenas ecoou para se pensar algumas questões educacionais, privilegiando as posições do projeto filosófico rortyano (Ghiraldelli Júnior, 1996; 1997) para criticar os 'criadores da desconfiança pós-moderna' (Ghiraldelli Júnior, 2001). Nas pesquisas que se apropriaram dos pensamentos de Foucault, Deleuze, Derrida, Baudrilard e Lyotard para pensar questões educacionais, raramente se percebe uma defesa das posições desses filósofos franceses utilizando a expressão pósmodernidade, excetuando-se quando VeigaNeto (1995) e, principalmente, Silva (1994; 1995) se referem à crise das metanarrativas e suas implicações para as teorias pedagógicas que até então haviam se fundado nelas, bem como a descentralização do sujeito moderno e os conseqüentes problemas da subjetividade para o ensino. Se nos estudos que se apropriaram tanto do pensamento rortyano quanto das posições desses filósofos franceses, a polêmica em questão foi arrefecida ou, mesmo, considerada irrelevante, nos trabalhos acadêmicos que os criticam a partir das posições de Jameson, Harvey e de certa tradição do marxismo, como os de Moraes (1996; 2004), ela foi recuperada para o debate em Filosofia da Educação, de modo a ocupar o seu centro, do mesmo modo que alguns dos estudos sobre o pensamento habermasiano, anteriormente mencionados, também o fizeram.

Nas produções acadêmicas resultantes dessas pesquisas ${ }^{1}$, o livro $A$ condição pós-moderna se configurou como uma referência importante, explicitamente ou não, porém raramente as obras subseqüentes a essa de Jean François Lyotard são mencionadas, deixando uma parte de seu legado filosófico de fora de tais discussões e, particularmente, de suas eventuais contribuições para a educação. Nota-se também que, nelas, os estudos que acentuaram a polêmica são os que se contrapõem às posições e aos projetos filosóficos considerados como pós-modernos, propondo a sua superação pelas filosofias que advogam a modernidade como um projeto inacabado ou, simplesmente, sustentam no projeto da modernidade um modo de solucionar os impasses da educação contemporânea. Nesses casos, também, a crítica à pós-modernidade repousa, dentre outras referências, sobre as teses expressas por Lyotard, no livro que preconizou a polêmica em questão, desconsiderando as suas produções antecedentes e, principalmente, subseqüentes à sua publicação, em que revê suas posições sobre o assunto e chega a criar uma outra designação para o que antes concebia como pós-moderno.

0 modo mais desejável de fazer Filosofia da Educação, a meu ver, é o de partir de questões ou temas educacionais relevantes ao

1. Agradeço a colaboração de Miriam Barretos Messias e de Tatiana de Faria Berto na revisão bibliográfica sobre o assunto. 
pesquisador para buscar nos pensamentos dos filósofos respostas àquilo que o interpelam, no presente, tal como desenvolvido em outras ocasiões (Pagni, 2004; 2005). Entretanto, não vejo como isso possa ser feito, com o necessário rigor, sem a contribuição de pesquisas que reconstituam seus projetos, o embate ou a confluência entre eles. Se, no presente, esse fazer filosofia da educação está se excedendo, muitas vezes formando círculos de pesquisadores sobre um determinado filósofo contemporâneo na educação, isso parece acontecer porque tais pesquisas aferram-se ao comentário de textos e não de projetos filosóficos, em que a educação pode ou não ser abordada. Assim, compreendo que esse trabalho de reconstituição de projetos filosóficos contemporâneos, seus embates e suas confluências, é ainda necessário à Filosofia da Educação, sobretudo, quando o projeto em questão foi pouco pesquisado no Brasil, muitas vezes reduzido a uma única obra ou circunscrito à polêmica da qual participou, excluído por certa tradição, nesse campo, como ocorreu com o de Lyotard.

Desse ponto de vista, o presente artigo procura desenvolver uma interpretação acerca do pensamento lyotardiano, privilegiando a análise das obras subseqüentes ao seu livro mais polêmico, com o objetivo de situar o seu projeto filosófico para além de um marco da pós-modernidade e de discutir as suas contribuições à Filosofia da Educação, na atualidade. Mediante tal interpretação, recupera-se um projeto filosófico que lança alguns 'desafios' à Filosofia da Educação referentes ao deslocamento de sua problemática epistemológica para a estética, nutrida por um pensamento capaz de elucidar a face complexa e obscura da educação, a sua sombra inumana, e o diferendo constitutivo do ensino, inapreensíveis pela linguagem e pela comunicação. Assim, esperamos que tal projeto possa ser compreendido não por aquilo que traz de polêmico à Filosofia da Educação, mas pelo que a desafia, no tempo presente, como uma rescrita da modernidade.

Em sua primeira parte, o artigo enuncia a posição sobre a pós-modernidade inicia- da por Lyotard, situando-a no contexto no qual se origina, assinalando a sua opção pela polêmica com Habermas, em vez da opção pela discussão, como alguns de seus contemporâneos franceses, e a problemática que confronta o ensino, no livro A condição pós-moderna. Em seguida, aborda o desenvolvimento subseqüente de seu projeto, demonstrando a revisão de suas posições em relação ao valor atribuído anteriormente às narrativas, até o ponto em que cria o conceito de diferendo, elege como problema das relações entre estética e política o sentimento (do) sublime e apresenta a rescrita da modernidade como alternativa à expressão pós-modernidade. Por fim, desse conceito, problema e alternativa, decorrentes de seu projeto, indicam-se algumas questões específicas que, à luz de sua filosofia, podem desafiar a Filosofia da Educação na contemporaneidade.

\section{Um diagnóstico sobre o saber e o ensino na pós-modernidade}

A publicação do livro La condition postmoderne de Jean François Lyotard, em 1979, parece ser um marco do debate modernidade versus pós-modernidade no campo filosófico. Na medida em que enuncia o problema do estatuto e, principalmente, da legitimação do saber na 'informatização da sociedade', reconhecendo que essa enunciação não seria original - a não ser no modo de analisar o referido problema -, Lyotard (2000) ${ }^{2}$ se refere a um contexto filosófico francês, no qual aquele problema adquiria certo sentido e do qual ele fazia parte.

Nesse contexto, Lyotard (2000) se posiciona como um filósofo antes do que um expert, isto é, como alguém que interroga o presente em vez de chegar a conclusões definitivas sobre ele. Isso não implica na assunção pelo filósofo francês de certa superioridade do

2. Utilizaremos aqui a sexta edição de $A$ condição pós-moderna, traduzida para o português por Ricardo Corrêa Barbosa, lembrando que, até a sua quarta edição (1986), o livro teve por título 0 pós-moderno e que, a partir da quinta edição, tenta recuperar o título original e ser mais fiel às idéias de seu autor. 
trabalho interrogante do filósofo frente ao saber conclusivo do expert, mas apenas no reconhecimento de gêneros de atividade e de olhares diferentes que, muitas vezes, se misturam nos discursos do cientista e do filósofo. Embora também reconheça o 'atalho um pouco sociologizante' presente na sua análise dos discursos (filosófico e ético-político) de legitimação do saber, ele o entende como necessário para situar melhor a problemática da legitimidade emergente do contexto filosófico no qual se encontra inserido. Por responder a essa demanda contextual, dedica $A$ condição pós-moderna ao Instituto Politécnico de Filosofia da Universidade de Paris VIIl, em Vincennes, colocando-se como elemento e como ator dessa instituição.

Criada em 1969, sob a denominação de Centre Universitaire Expérimental de Vincennes, inspirada em maio de 1968, tal centro buscou uma outra relação entre professor e aluno, capaz de romper as suas formas tradicionais, bem como experimentar relações entre os saberes no ensino e na pesquisa. Desde a sua criação até o final dos anos 1970, ela aglutinou intelectuais que, posteriormente, se tornariam bastante conhecidos como Lacan, Châtelet, Foucault, Popper, Deleuze, Lyotard, entre outros. Alguns desses intelectuais com propensões de esquerda deram o tom da discussão acadêmica no instituto, especialmente no Departamento de Filosofia fundado por Foucault que, com o apoio de Aron e Canguilhem, recrutou boa parte de seus integrantes e concorreu para o projeto departamental e da universidade. Em tal projeto, a filosofia não seria tratada como um campo disciplinar, a parte de outros campos da produção em Ciências Humanas e, particularmente, das Artes, como o cinema, a literatura, o teatro, a música e a dança. Ao contrário, buscava-se nesse projeto a relação da filosofia com esses outros campos, não obstante o fato de que alguns dos integrantes do Departamento continuarem trabalhando com pesquisas mais especializadas nesse campo disciplinar, concentrados na historiografia da Filosofia e em Filosofia das Ciências. Essa diver- sidade era tolerada e, muitas vezes, acirrava o debate no Departamento. Porém, o que parece ter prevalecido no desenvolvimento desse projeto foi essa relação com as Artes. Isso é evidenciado com a sua mudança para Saint Dennis, em 1980, com a criação de um instituto politécnico que procurou associar as artes à Filosofia e, particularmente, à Estética, efetivando um projeto que, praticamente, continua sendo seguido no instituto de Arts, Philosophie et Esthétique de l'Université Paris VIIl até os dias de hoje. É a essa inteface de vários campos do saber, com preponderância do estético e do político na produção do saber universitário, e a esse clima vivido na Universidade de Paris VIll, em função do projeto iniciado com sua criação em Vincennes, que lyotard se refere na introdução de $A$ condição pós-moderna.

Lyotard (2000) parece sintetizar as posições filosóficas emergentes nesse contexto intelectual francês, expressas nas suas obras, bem como nas de Foucault, Deleuze, Baudrilard e Derrida, no debate entre eles, de certo modo, assumindo a designação de pós-modernidade como uma condição do tempo presente, sob a qual emergira o movimento empreendido por esses filósofos franceses. É importante assinalar, porém, que tais filósofos - com exceção de Baudrilard - jamais assumiram tal designação, especialmente quando ela se tornou polêmica, após a publicação do livro de Lyotard, ocorrida um ano antes do início das críticas ao denominado pós-modernismo dos 'jovens conservadores' franceses (Habermas, 1992) ou de certo 'anarquismo' dos 'neoconservadores', desenvolvidas por Habermas (1990).

0 filósofo alemão começa a esboçar essa crítica à pós-modernidade em 1980, quando profere a conferência Modernidade - um projeto inacabado, na ocasião em que recebe o prêmio Adorno, em Frankfurt, e a desenvolve mais detalhadamente em seu livro Discurso filosófico da modernidade, publicado em 1984. Como diz Habermas (1990, p. 11) nesse livro, "o polêmico e multifacetado tema da modernidade" o teria acompanhado pelo inte- 
resse público despertado sobre os seus aspectos filosóficos, em virtude da recepção do neoestruturalismo francês, o mesmo ocorrendo em relação ao tema da pós-modernidade, com a publicação do livro La condition postmoderne de Jean François Lyotard, em 1979. Na conferência, ao compreender a "modernidade como um projeto inacabado”, Habermas (1992, p. 121) concebe a pós-modernidade como um "antimodernismo" e um meio de expressão das posições dos "jovens conservadores", de "George Bataille à Derrida, passando por Foucault", que se apropriam da experiência da modernidade estética, almejando uma "subjetividade descentrada, liberta de todas as restrições da cognição e da atividade voltada para fins, de todos os imperativos do trabalho e da utilidade" (p. 122), afastando-se do mundo moderno. No livro, ao responder aos desafios lançados pela crítica à razão moderna, desenvolvida pelos 'neo-estruturalistas franceses', Habermas (1990) procura reconstruir o discurso filosófico da modernidade, demonstrando o quanto este é fecundo como tema filosófico e como projeto inacabado, contrapondo-se às posições políticas acerca do fim da história, postulada pelos neoconservadores, e do fim do iluminismo, advogadas pelos anarquistas anteriormente denominados de 'jovens-conservadores' -, entre os defensores da pós-modernidade.

0 livro de Lyotard (2000), de certo modo, respalda as críticas do filósofo alemão e a divisão que estabelece entre os defensores da modernidade e os da pós-modernidade, algo que Michel Foucault tentou evitar. Isso porque parte dos filósofos franceses que lhes são próximos, $\log$ o após essas críticas, adotam a perspectiva de estabelecer confluências entre seus pensamentos e os da primeira geração da Escola de Frankfurt, voltando contra o seu herdeiro mais importante, Habermas, o legado de seus mestres. No entanto, como sugere Eribon (1996), Foucault utiliza a estratégia de não polemizar direta e publicamente com o filósofo alemão ou com qualquer outro intelectual. Em uma entrevista a Paul Rabinow, quando perguntado os motivos dessa esquiva, ele argu- menta que ele gosta de 'discussão', mas não de 'polêmica', porque uma ética, “que diz respeito à pesquisa da verdade e a relação com outro, está em jogo" (apud Eribon, 1996, p. 180181): se naquela um "jogo sério de perguntas e respostas, no trabalho de elucidação recíproca, os direitos de cada pessoa são, de certo modo, reciprocos”. Em contrapartida, nessa forma de interlocução, diz ele: "o polemista avança armado de privilégios que possui logo de saída [...] ele detêm o direito que o autoriza guerrear e a fazer dessa batalha um empreendimento justo" (apud Eribon, 1996, p. 180-181).

Ao contrário dessa estratégia, no contexto filosófico francês, o livro de lyotard polemiza com a teoria habermasiana do agir comunicativo, propondo uma alternativa teórica a ela. Embora esboce um diagnóstico do presente, como seus contemporâneos franceses, Lyotard (2000) propõe um objeto, um recorte, algumas questões e uma abordagem para pensá-lo, diferenciando-se e se singularizando em relação às suas teses e filosofias. Por sua vez, isso não significa que admita ter privilégios logo de saída ou de autorizar-se a fazer da batalha um empreendimento justo em relação à teoria habermasiana, mas apenas fazer da polêmica com ela um modo de elaborar melhor suas posições acerca da pós-modernidade e, conseqüentemente, contemplá-las em seu projeto filosófico.

Em sintese, pode-se dizer que o recorte estabelecido por Lyotard (2000, p. xv) sobre o objeto desse livro é a posição do saber "após o estado da cultura após as transformações que afetaram as regras dos jogos das ciências, da literatura e das artes a partir do final do século XIX”. Ao analisar esse objeto, o seu objetivo é explicitar a "crise dos relatos" ou das narrativas que afligem o saber científico nas "sociedades mais desenvolvidas" e que geraram uma condição de incredulidade nas metanarrativas em que, até então, o legitimaram, a qual denomina de pós-moderna. Diante de tal condição, Lyotard (2000) investiga a questão acerca de onde se poderia encontrar a legitimidade, já 
que o critério atual do saber científico e de sua pragmática seria tecnológico, impossibilitando que ele julgasse o 'verdadeiro' e o 'justo'. Ao polemizar com a resposta habermasiana de que o critério de legitimidade do saber poderia ser restabelecido por meio da discussão e do consenso, o filósofo francês a questiona em relação à violência que estabelece contra a 'heterogeneidade dos jogos de linguagem' constitutivos da pragmática do saber narrativo e científico, na condição pós-moderna.

Para isso, ele recorre à categoria wittgensteiniana de jogos de linguagem, reinterpretando-a a partir do que denomina de 'agonismo geral' ou da 'linguagem' e a convertendo em uma espécie de método. Pois Lyotard (2000) entende que os jogos de linguagem podem compreender as diversas categorias de enunciados, determinados por "regras que especifiquem a sua propriedade e pelo uso que delas se pode fazer" (p. 17), analogamente ao jogo de xadrez, cujas regras determinariam a propriedade de cada peça e o modo de seu deslocamento no tabuleiro. Por essa caracterização geral, as regras dos jogos de linguagem não teriam legitimidade em si mesmas, mas em um "contrato explícito ou não entre os jogadores”, sem os quais não existiria jogo e a sua natureza poderia ser modificada por meio de um lance, o que levaria a conceber todo enunciado como sendo um lance feito num jogo. Da perspectiva de uma 'agonística geral', proviria um ato de linguagem e um método que pressupõe que "falar é combater, no sentido de jogar" não apenas com a finalidade de ganhar, como também para realizar um lance pelo simples prazer de inventá-lo, ainda que essa possibilidade não perca de vista "o sentimento de sucesso" sobre um adversário de envergadura: "o da língua estabelecida, o da conotação" (Lyotard, 2000, p. 17). Nesse sentido, não se deveria ocultar um princípio complementar que norteia a sua análise: o de que "o vínculo social observável é feito de "lances de linguagem" e, como tal, estaria sujeito às variações de sua natureza eminentemente social.
Com esse olhar interpretativo sobre o que denomina de condição pós-moderna, Lyotard (2000) se singulariza de seus contemporâneos franceses e polemiza com as teses de Habermas. Afinal, considera que, até a modernidade, as metanarrativas (da dialética do espírito, da hermenêutica do sentido ou da emancipação do sujeito racional ou do trabalhador) se constituíram em um meio de conciliar a pragmática do saber científico com a do saber narrativo, unindo os gêneros de discurso denotativo da primeira com os gêneros prescritivos, exortativos e avaliativos da segunda. Assim, segundo ele, as esferas do conhecimento cognitivo seriam integradas com as do julgamento ético e da decisão política, conferindo às ciências um critério para o verdadeiro e, de certo modo, para o justo. Contudo, com o descrédito em relação às metanarrativas na pós-modernidade, essa conciliação passaria a ser efetuada pela performance, na comunicação dos enunciados desses gêneros de discurso, indistintamente; a sua validade se configuraria pelo consenso em torno deles e o seu desempenho medido pelo seu assentimento ou não pela comunidade. Embora seja diferente do jogo dialético da pesquisa científica, o ensino reforçaria, por meio da didática, a distribuição dos enunciados considerados válidos do saber científico. 0 pressuposto para essa didática seria o de que, na comunicação que a compreende, o estudante que não sabe é o destinatário do remetente que sabe - o professor -, havendo algo a aprender e com o seu aprendizado tornar-se um expert como o mestre. Para tanto, seria preciso pressupor também que os enunciados, transmitidos no ensino, estivessem pautados na argumentação e na administração das provas, do mesmo modo que a pesquisa, a fim de que pudessem ser considerados como similares ao mesmo regime de verdade das ciências. Dessa forma, o expert introduz o estudante no "no jogo de formação do saber científico", buscando formá-lo segundo uma figura do especialista, como seu mestre, por meio da transmissão do saber e também pelo aprendizado da habilidade de pesquisar o que não sabe, ade- 
quando essa atividade ao mesmo regime de verdade e regras do saber científico (Lyotard, 2000, p. 44-46).

0 problema assinalado pelo filósofo francês, porém, é o de que, ao adequar-se ao mesmo regime de verdade e de regulamentação do saber científico, a transmissão de seus enunciados e o aprendizado da habilidade de pesquisar, em que consiste o ensino, passa pela mesma crise de legitimação, mediante a qual os relatos especulativos são substituídos pelo critério de desempenho. Com a informatização das sociedades, segundo ele, as redes de comunicação ocuparam o papel da distribuição dos enunciados verdadeiros, desempenhados pelo ensino, e o lugar do mestre seria colocado em xeque, podendo ser substituído pelo computador, já que se trataria de mera transmissão de dados, de informação, cujo armazenamento na memória da máquina seria superior ao do homem. Por seu turno, como a produção do saber científico e o processo da pesquisa científica são determinados pela comunidade de experts aos quais se destina, o aprendizado do pesquisar encontra-se restrito aos problemas estabelecidos, muitas vezes atinentes ao aprimoramento do funcionamento do sistema, sem que se escape as suas redes de informação e de controle. Tanto a distribuição dos enunciados do saber científico quanto o aprendizado da habilidade de pesquisar, que caracterizam o ensino, seriam administrados pelo sistema. Assim, o ensino também se pautaria na performance do saber científico, em sua aplicação às esferas da vida humana e à matéria, convertendo-se em uma tecnologia que, em nome do desenvolvimento, manteria intacta as injustiças, as desigualdades entre o primeiro e o terceiro, o terror e o poder vigentes em uma sociedade totalmente regida pelo desempenho (Lyotard, 2000).

Diante desse diagnóstico, a alternativa proposta por lyotard (2000) é a de um critério de legitimação do saber científico e do ensino, que se paute na pesquisa da instabilidade e na paralogia dos inventores. Para ele, a pesquisa da instabilidade reconheceria o cará- ter indeterminado também da ciência, elucidando seu aspecto não assertivo, movido por aquilo que a linguagem não consegue apreender pelo conceito. Se as metanarrativas seriam inviáveis para a legitimação desse saber, sob a condição pós-moderna, restaria, então, o "pequeno relato" como forma de expressão da “invenção imaginativa”: produtora de lances capazes de modificar as regras em/do jogo e o assentimento estabelecido por uma comunidade, em torno de enunciados consensualmente estabelecidos como válidos, produzindo assim o dissenso, ao invés do consenso, e reativando o conseqüente fluxo das descobertas. São esses lances "de importância muitas vezes desconhecida de imediato", segundo Lyotard (2000, p. 99-134), que caracterizariam a paralogia dos inventores não para produzir a novidade utilizada pelo sistema para melhorar a sua eficiência, mas principalmente para contrapor-se ao consensualmente estabelecido no âmbito desse saber e, quem sabe, aos efeitos de poder que dele resultam em sua aplicação ao existente.

Por meio dessas indicações, Lyotard (2000) questiona se esse novo lance no jogo do saber científico e no ensino poderia ocorrer por meio do jogo de experimentação sobre a linguagem, presente tanto no processo de produção quanto no de transmissão de saberes. A sua resposta a essa pergunta é afirmativa, desde que as universidades abrissem suas oficinas de criação e, juntamente com outras instituições, ultrapassassem os seus limites, sob a condição pós-moderna. Para ele, vários campos do conhecimento, sobretudo os das ciências humanas, poderiam reflexionar sobre as suas próprias produções, sobre os objetos e os problemas que elegeram para análise, compreendendo os jogos de linguagem que os abarcaram, vendo neles um processo de estetização similar ao da arte e elucidando aquela dimensão da linguagem até então excluída da pragmática do saber científico. Ao mesmo tempo em que vários professores, responsáveis pela transmissão desses saberes na universidade, e não apenas nela, poderiam resultar na assunção de tal atitude, 
no ensino, as suas proximidades com a arte e explicitar os jogos de linguagem que o compreendem, até chegar ao seu caráter inefável e criador. Assim, eles poderiam se contrapor à restrição atual do ensino aos aspectos cognitivos ou lógicos da linguagem e à sua substituição pela linguagem computacional: bastaria que, para isso, considerassem que o processo de produção do conhecimento e o núcleo artístico da educação poderiam oferecer ao pensamento um outro critério, mais justo e, sobretudo, mais sublime, para resistir ao princípio de desempenho e à performatividade inscritas nessas atividades.

Essa é a problemática indicada, pelo livro A condição pós-moderna, para ser enfrentada pelos professores e que confronta o ensino, sob a condição pós-moderna. Se tal problemática foi retomada em outras ocasiões pelo filósofo francês, os elementos teóricos para se pensar o que seria esse núcleo artístico da educação e quais seriam os critérios justo e, sobretudo, sublime para que o ensino se tornasse uma prática política, dentre outras, capaz de resistir ao existente, ainda não se encontram nele elaborados. No desenvolvimento de seu projeto filosófico, ele parece fornecer mais elementos para enfrentar essas questões salientadas, depreendidas da interpretação do livro de Lyotard (2000), que desafia a filosofia e a educação, na contemporaneidade, bem como continua a intervir na polêmica sobre a pós-modernidade, de modo a singularizar suas posições frente às de seus críticos e, sob alguns aspectos, revisá-las.

\section{Da pós-modernidade à rescrita da modernidade}

Se a alternativa proposta pelo livro de Lyotard (2000), à condição do saber científico e ao ensino na pós-modernidade, contrapõe-se a de Habermas e singulariza o seu pensamento dentre os de seus contemporâneos franceses em suas obras subseqüentes, o próprio termo pós-moderno é colocado em questão e há um gradativo deslocamento dessa polêmica. Afinal, não se pode ignorar que tal livro, como assinala o próprio Lyotard (2000, p. XVII), é um "escrito de circunstância", encomendado pelo Conselho das Universidades do Governo de Quebec. Nem se pode esquecer que tal polêmica se constitui em um momento ou em uma parte do desenvolvimento de seu projeto filosófico, iniciado nos anos 1960, que não se restringe a caracterizar a pós-modernidade, mas se propõe a responder aos desafios do tempo presente de um ponto de vista filosófico e político.

Embora possa se considerar que a polêmica em questão possa ter contribuído para o desenvolvimento de seu projeto, não se pode restringir o projeto filosófico lyotardiano a ela. $\mathrm{Na}$ continuidade da polêmica com Lyotard, os filósofos que, posteriormente, se contrapuseram as posições de lyotard e de Habermas, como Fredric Jameson (apud Hutcheon, 2002) e, principalmente, Richard Rorty (1999; 2002), não ignoraram essa vinculação das posições em jogo sobre o assunto com os seus respectivos projetos filosóficos. Ao contrário, também o fizeram para colocar nesse embate as suas próprias posições alicerçadas em seus projetos filosóficos distintos dos de Lyotard e de Habermas. Afinal, o que está em jogo no cenário filosófico, entre os anos 1980 e meados dos anos 1990, são essas filosofias, dentre outras, que redundam em posições filosóficas e políticas distintas acerca do tempo presente e implicam projetos diferentes.

Por esse motivo, mesmo que se coloque em questão a restrição do projeto filosófico lyotardiano a um 'escrito de circunstância', não se pode ignorar que ele se constrói em torno dos embates sobre a pós-modernidade. Porém, também não se pode esquecer que, concomitantemente a tais embates, Lyotard desenvolveu seu projeto filosófico, concentrando-se na elaboração do livro Le différend, publicado em 1983, à luz do qual sustenta as suas teses em torno das ligações entre estética e política, como um campo fecundo à filosofia, revendo o que entendia por pós-modernidade e a ênfase dada às narrativas. Ao criar o conceito de diferendo, eleger o sentimento (do) sublime como um elemento de interpelação do pensamento e 
como um problema das ligações entre estética e política em sua filosofia, o filósofo francês parece desafiar a própria filosofia e, como será visto mais adiante, fornecer questões desafiadoras à Filosofia da Educação.

Em uma coletânea, sob o título $O$ pósmoderno explicado às crianças, publicada em 1986, Lyotard (1993, p. 33) afirma ter exagerado na importância atribuída ao "gênero narrativo”, em A condição pós-moderna, identificando o conhecimento com ele, porém só percebeu isso em uma "pesquisa mais longa e radical", que resultou em Le différend. Após tal pesquisa, ele diz concentrar os esforços de sua filosofia em "distinguir regimes de frases" e "gêneros de discursos diferentes", pois entende que, embora permitissem "escapar à crise da deslegitimação", as "pequenas narrativas" também não teriam "valor de legitimação". Dessa forma, Lyotard (1993) procura explicitar os diferendos entre o gênero narrativo e o do conhecimento científico, mostrando o quanto este se encontra impregnado por aquele que, por sua vez, não tem valor de legitimação, em função de sua inconsistência e de sua dificuldade de estar sujeito à prova.

Após a publicação de Le différend ${ }^{3}$, então, o conceito de diferendo passa não apenas a ser determinante para a sua filosofia, como também a determinar o seu projeto filosófico. 0 diferendo é um conceito criado para explicitar, como explica lyotard (1999, p. 9), não um litígio, mas "um caso de conflito entre pelo menos duas partes” em que os gêneros discursivos em disputa não podem ser julgados em virtude da ausência de uma regra comum que possa ser aplicada a cada um deles. Se um desses gêneros em conflito for julgado pelas regras de um outro, em função de uma inferência sem razão de ser ou de uma arbitrariedade, o resultado desse julgamento implica em prejuízo para uma das partes. Nesse sentido, o diferendo "é o estado inestável da linguagem e o instante em que algo que poderia se expressar não pode fazê-lo", implicando "no silêncio como uma proposição negativa, mas que, em princípio, apela também para proposi- ções possíveis" (Lyotard, 1999, p. 25-26). 0 sentimento seria um sinal desse estado, sendo necessário procurar encontrar "as novas regras de formação e de encadeamento de proposições capazes de expressar o diferendo" revelado por tal sentimento se não quiser que aquele se transforme em um litígio e esse sinal de alerta não seja inútil. Essa procura deveria ser o objetivo "de uma literatura, de uma filosofia e, talvez, de uma política" que "explicitam os diferendos e encontram seus idiomas" (Lyotard, 1999, p. 26).

Nutrido pelos diferendos entre os gêneros discursivos e, eventualmente, por encontros entre eles, como diz Lyotard (1999, p. 182), o discurso filosófico se manteria "no exame crítico" das frases, constituindo-se em um gênero diferente do narrativo. Sem se sobrepor a ele, e aos demais gêneros, por ser portador do universal a partir do qual definiria o que é eticamente justo ou deveria ser politicamente superior, conforme um fim cosmopolita, o discurso filosófico, justamente por saber que não seria uma metanarrativa, se reconheceria como um gênero em busca de suas regras. Sob esse aspecto, o gênero filosófico poderia se aproximar do gênero literário ou da narrativa. Embora a crítica não fosse o compromisso desses gêneros como eles, o gênero filosófico dá o que pensar por meio de seu discurso: problemas significativos que se apresentam a percepção e podem produzir o sentimento (do) sublime, tal como a literatura e algumas narrativas, desafiando o pensamento dos portadores de nomes próprios, afetados por esse acontecimento, a voltarem-no ao desconhecido e ao incomensurável, no presente, para resistir ao passado que sobre ele incide, não sem angústia, para vislumbrar algum futuro.

Analogamente às produções da vanguarda artística que serviram, senão de modelo, ao menos de inspiração para o filósofo francês, esse dar o que pensar deveria salvar a honra do

3. Utilizarei a versão espanhola desse livro, traduzida por Alberto L. Bixio, com o título La Diferencia. 
pensamento, no presente, por meio do exercício da crítica e de um esforço para se presentificar o impresentificável. Se o impresentificável não pode ser completamente traduzivel no idioma existente, necessitando da criação de um outro idioma nem pode ser comunicado, argumentativa e conceitualmente, a crítica e o esforço de presentificá-lo pode recorrer a outros gêneros, dentre eles às narrativas ou à poética. Isso não significa valorizar as pequenas narrativas como um escape à crise das metanarrativas, mas apenas uma estratégia dentre outras possíveis no jogo de linguagem e de poder existentes, tendo em vista essa explicitação dos diferendos, que tem como alvo do filosofar a intensificação do sentimento (do) sublime.

lsso porque Lyotard (1993, p. 22) entende que o conhecimento científico, a indústria e a economia capitalista "divulgam uma das regras às quais a sua possibilidade está submetida", a saber: a de que "não há realidade que não seja atestada por um consenso entre parceiros sobre conhecimentos e compromissos". Esse enfraquecimento da crença na realidade e da descoberta do pouco que lhe resta, "associada à invenção de outras realidades”, seria inseparável da modernidade, independente de sua historicidade. No duplo movimento de enfraquecimento da crença na realidade e da invenção de outras realidades, segundo ele, pode ser notado o móvel da modernidade, que a partir da estética kantiana do sublime, impulsionou a arte moderna e se tornou um axioma das vanguardas artísticas.

Para ele, o sentimento (do) sublime seria, em termos kantianos, uma "afecção forte e equívoca" que compreende prazer e dor, ao mesmo tempo; em que o prazer deriva da dor, da falta, de uma ausência, característica do conflito das faculdades de conceber e de presentificar algo. Tendo em vista tal interpretação, Lyotard (1993, p. 22-23) desenvolve seus argumentos de modo a sugerir que Habermas se pautaria antes em uma estética do belo do que em uma estética do sublime. Isso porque, segundo a sua interpretação de Kant, a estética do belo pressuporia que o conhecimento só seria possível se, primeiro, "o enunciado fosse inteligível" e, depois, dele pudesse se extrair "casos" de experiência que the correspondam. Nesse sentido, haveria beleza se, em tal ocorrência do "caso" (a obra de arte) em que a afecção se desse sem a determinação conceitual, "o sentimento de prazer", independente do interesse suscitado pela obra, apelasse a um "consenso universal de princípio (que talvez nunca seja obtido)". Em tal sentimento de beleza, assim, o gosto atestaria que, "entre a capacidade de conceber e a capacidade de 'presentificar' um objeto correspondente ao conceito, um acordo não determinado, sem regra", daria lugar a um "juízo reflexivo", sentido sob a forma de prazer. Diversamente, o sublime ocorre quando "a imaginação falha ao 'presentificar' um objeto que venha a entrar, nem que seja apenas em princípio, em concordância com um conceito" (Lyotard, 1993, p. 22). Com o sublime não ocorreria "presentificação" possível; não haveria possibilidade de qualquer conhecimento da realidade ou da experiência, mas a proibição da concordância livre das faculdades que produzem o sentimento do belo e o impedimento da formação e da estabilização do gosto, porque tal experiência ou realidade seriam "impresentificáveis".

0 diferendo da estética moderna seria, de acordo com Lyotard (1993, p. 26), o de que "é uma estética do sublime, mas nostálgica", pois "permite que o 'impresentificável' seja alegado apenas como um conteúdo ausente, mas a forma continua a proporcionar ao leitor ou ao espectador, graças à sua consistência reconhecível, matéria para consolação e prazer”. Para ele, tais sentimentos não formariam "o verdadeiro sentimento sublime”, isto é, uma combinação de prazer e dor: "o prazer de que a razão exceda qualquer 'presentificação', a dor de que a imaginação ou a sensibilidade não estejam à altura do conceito”. Esse seria o sentimento que teria sido esquecido na e pela modernidade, cabendo ao pós-moderno lembrála disso, se perfazer nele e por ele. De acordo com Lyotard (1993): 
0 pós moderno seria aquilo que no moderno alega o 'impresentificável' na própria 'presentificação’; aquilo que se recusa na consolação das boas formas, ao consenso de um gosto que permitiria sentir em comum a nostalgia impossível; aquilo que se investiga com 'presentificações' novas não para desfrutá-las, mas para melhor fazer sentir o que há de 'impresentificável'. (p. 26)

Do mesmo modo que um filósofo, um artista e um escritor pós-moderno trabalham sem regras, em uma busca sem fim naquilo que fez e que continua a fazer. Como o filósofo, as suas obras têm as propriedades do acontecimento, por esse motivo elas chegam tarde ou a sua preparação comece demasiado cedo aos seus autores. 0 pós-moderno deveria ser entendido, conforme Lyotard (1993, p. 26), "segundo o paradoxo do futuro (pós) anterior (modo)”. Em outras palavras, o pós-moderno não seria o fim do modernismo, mas o seu estado nascente e constante. Não haveria obra que se pretendesse ser moderna sem ser antes pós-moderna, já que esse termo seria usado para designar um esquecimento daquilo que a modernidade foi em seu início, do sublime que a impulsionou e a impulsiona, de seu nascimento, metaforicamente falando.

Para a pós-modernidade, diz lyotard (1993, p. 27): "não competiria fornecer realidade, mas inventar alusões ao concebível que não pode ser 'presentificado'”, sem que se espere a "menor reconciliação entre "jogos de linguagem' em relação aos quais Kant, sob o nome de 'faculdades', sabia que estão separados por um abismo". Somente a ilusão transcendente (a de Hegel) poderia “esperar totalizá-los numa unidade real”, mesmo sabendo que o preço a ser pago por ela seria o terror. Segundo Lyotard (1993), já teríamos pagado esse preço o suficiente durante os séculos XIX e XX, mas ainda continuariamos a ouvir murmúrios sobre essa ilusão. Contra ele, a resposta seria: "guerra ao todo, testemunhemos em favor do "impresentificável', ativemos os diferendos, salvemos a honra do nome" (Lyotard, 1993, p. 27). Essa é a espécie de mantra recitado pelo filósofo fran- cês na polêmica com Habermas, nesse contexto. Se Habermas defende uma estética do belo e do inacabamento da modernidade, dessa forma, nesses termos, Lyotard postula uma estética do sublime e a recordação daquilo que essa mesma modernidade esqueceu e que denomina de pós-moderno. Nesses termos, para o filósofo francês, a pós-modernidade não seria o que vem depois da modernidade, cronológica e historicamente falando, mas o que vem antes e a acompanha, relembrando seus crimes e suas atrocidades, alertando-a sobre a sua barbárie. Depois de Adorno, diz Lyotard (1993, p. 95), “usei o termo 'Auschwitz' para significar o quanto à matéria da história ocidental recente parece inconsistente relativamente ao projeto 'moderno' de emancipação da humanidade”. Ele se refere, assim, à necessidade de uma elaboração desse signo que contradiz esse projeto e que ajudaria a nos defrontarmos com essa espécie de tristeza do espírito do tempo, sem que isso implicasse na orientação para uma nova perspectiva, e sim em recobrar um "esquecimento inicial".

Para o filósofo francês, esse movimento estaria presente nas vanguardas artísticas que inspiram a sua atitude filosófica. Ele se constituiria em um trabalho "longo, obstinado, altamente responsável, orientado para a procura das pressuposições implicadas na modernidade" (Lyotard, 1993, p. 97). Ele poderia ser concebido, analogamente, ao trabalho de perlaboração, nos termos da terapia psicanalítica, isto é, como uma tentativa de a modernidade elaborar "a sua perturbação presente associando livremente elementos aparentemente inconsistentes como situações passadas" (1993, p. 97), com a finalidade de descobrir seus próprios "sentidos ocultos". Se essa responsabilidade para com tal trabalho fosse abandonada por parte da filosofia, segundo ele, estaríamos condenados a repetir o passado em seus aspectos mais sombrios e a fonte da infelicidade que nos abateram durante dois séculos, sob a denominação de modernidade. Por esse motivo, considera ser essa a responsabilidade das vanguardas artísticas e, por assim dizer, intelectuais ou filosóficas na pós-modernidade. 
Com a publicação do livro 0 inumano, em 1988, Lyotard (1997) compreende essa responsabilidade como uma das tarefas da rescrita da modernidade: termo que começa a preferir em função de precisar melhor a resistência à não-circunscrição da modernidade a um registro meramente temporal, histórico e cronológico, à expressão pós-modernidade que, por sua vez, teria se tornado uma acepção a mais no mercado das ideologias em seu uso corrente. Nesse seu primeiro sentido, a rescrita $d a$ modernidade consistiria em um trabalho de perlaboração sobre a própria modernidade, tal como o filósofo francês havia apresentado na revisão de sua compreensão sobre a pósmodernidade, nos termos anteriormente desenvolvidos. Isso não implicaria no retorno ao começo da modernidade, na relembrança do que esqueceu e no resultado de sua cura de uma melancolia constante produzida ao longo de seu desenvolvimento, mas em um trabalho que se dedicaria "a pensar no que, do acontecimento e do sentido do acontecimento, nos é escondido de forma constitutiva" (Lyotard, 1997, p. 35). Esse objeto do pensar não seria apenas oferecido por um pressuposto anterior a si mesmo, como também pelas dimensões futuras que compreendem o projeto, o programa ou mesmo a proposição e o propósito de produzir essa perlaboração na forma de um relato, de uma narrativa.

Em tal narrativa, a associação livre do pensado com as coisas passadas e presentes, ocultas e silenciosas, se daria não como uma relembrança com a finalidade da cura nos termos psicanalíticos, mas como um trabalho sem fim, cuja regra não está pressuposta no princípio, para escrever mais e realizar a modernidade. 0 filósofo francês discorda, dessa forma, dos fins da perlaboração e do modo como a associação livre foi concebida por Freud, em sua aplicação à técnica analítica. Embora tenha pensado essa técnica como uma arte, segundo Lyotard (1997, p. 40), Freud a teria pensado como um elemento constitutivo do processo de emancipação. Essa hipótese não seria plausível pelo filósofo francês, preferindo a do sublime kantiano, conforme já o vinha pensando em seu projeto, nos termos anteriormente apresentados, pois, compreende que, ao estar libertada das formas a priori do entendimento, essa estética propiciaria os mesmos efeitos da associação livre. Isso porque a beleza do fenômeno percebido seria proporcional à sua fluidez, mobilidade e efemeridade, assim como "a imaginação daria 'muito a pensar' ao espírito, muito mais do que o trabalho conceitual do entendimento o possa fazer".

Nesse ponto, a sua tese se ligaria à questão da temporalidade implicada no outro sentido da rescrita da modernidade, indicado por Lyotard (1997, p. 33): o de que o prefixo "re" dessa rescrita realçaria a futilidade de qualquer "periodização histórica cultural", do “antes” (pré) e do depois ("pós”), pelo simples fato de não resolver o problema do presente, que consiste em determinar a diferença entre "o que aconteceu" (o proteron) e "o que está para acontecer" (o husteron), sem situá-los em face a um "agora". Para ele, tal periodização ou cronologia não poderia ser determinada, caso não nos apoderássemos desse "agora", já que este seria "constantemente arrastado por aquilo que chamamos o fluxo da consciência, o curso da vida, das coisas, dos acontecimentos" (p. 33). Dessa forma, nunca chegaria a ser "demasiado cedo nem demasiado tarde ao mesmo tempo para que qualquer coisa como um 'agora' possa ser apreendido de uma maneira identificável” ( p. 33).

Para o filósofo francês, sempre haveria excessos sobre a intenção de identificar e sobre o projeto de apreender um "sendo" que seja "aqui" e "agora”, a própria coisa em si: haja vista que, quando aplicado à modernidade e à pósmodernidade, identificada e circunscritas como entidades históricas em que a segunda sucede à primeira. Assim interpretada, segundo Lyotard (1997, p. 34-35), “a modernidade está grávida do seu pós-modernismo" e a sua rescrita seria a do começar do zero, a das pretensões de ruptura com o passado e de inauguração de uma nova era: o que somente seria por intermédio de 
um domínio do tempo, estabelecido pela síntese conceitual, para que fosse disposto em uma cronologia que ordenasse o passado e o futuro a partir do presente.

Todavia, é justamente esse domínio do tempo por meio de uma síntese conceitual que o primeiro sentido da rescrita da modernidade procura renunciar na medida em que preconiza "a apreensão da estética das formas" - não a "recognição" - e "a aptidão para deixar aparecer as coisas da forma como se apresentam", com uma atitude de que, cada momento, cada "agora", seria como se fosse um "abrir-se a" (Lyotard, 1997, p. 41). Desse modo, o filósofo francês considera que "a modernidade é, afinal, a sua própria rescrita" e a entende nos seguintes termos:

Reescrever, como o entendo aqui, diz respeito à anamnese da Coisa. Não só a Coisa que representa o ponto de partida para uma singularidade dita 'individual', mas a Coisa que assombra 'a linguagem', a tradição, o material com o qual, contra o qual e no qual se escreve. Assim, a reescrita depende tanto de uma problemática do sublime, e hoje ainda mais e mais obviamente, do que do belo. Isso abre a grande porta para a questão das relações entre estética e ética. (p. 42)

Nesses termos, a rescrita da modernidade não estaria relacionada com a pós-modernidade e, muito menos, com a sua conversão no mercado das ideologias. Embora já tivesse se utilizado desse termo em outra ocasião, a pós-modernidade foi, segundo ele, uma "forma provocatória" para "deslocar o debate do conhecimento", que não implicava na postulação de uma nova era e sim em uma "reescrita de traços reivindicados pela modernidade", que estariam nela inscritos há muito tempo. Com a rescrita da modernidade, o seu objetivo seria apenas dar voz a esses traços, dentro dos limites anteriormente enunciados, para que a própria modernidade desenvolva um trabalho de perlaboração sobre si mesma. 0 problema é que, com a introdução das novas tecnologias na produção, na difusão, na distribuição e no consumo dos bens culturais e com a transformação das unidades de informação em bits, já não se trataria de "formas livres das aqui e agora à sensibilidade e à imaginação" (1997, p. 43). Então, caso se admita que a perlaboração fosse assunto da livre imaginação e exigiria o desdobrar do tempo entre o “ainda não", "já não" e "agora”, o que poderia ser preservado disso e conservado após essa era de novas tecnologias? Como poderia a perlaboração esquivar-se da lei do conceito, da recognição e da predição, em um momento em que unidades de bits seriam constituídas a partir das formas lógicas e das regras provenientes desses gêneros? A resposta dada por Lyotard (1997) a essas perguntas é a de que se contentaria que a rescrita $d a$ modernidade resistisse à escrita dessa suposta pósmodernidade.

Ao se colocar essas questões e respondêlas desse modo, Lyotard parece retomar o diagnóstico do presente, esboçado em $A$ condição pós-moderna para, então, separar o que nele ainda consideraria atual, quase dez anos depois, e criar uma outra denominação, por meio de conceitos, problemas e perspectivas desenvolvidos em seu projeto filosófico, ao que entendia por pós-modernidade: a rescrita da modernidade. Ele parece escapar, dessa forma, da polêmica provocada pelo seu livro e pela designação pós-modernidade, em um momento em que os debates mais intensos sobre ela haviam se arrefecido ou que a ele somente interessava polemizar sobre a discussão.

\section{‘Desafios' lyotardianos à Filosofia da Educação}

Embora não se refira diretamente ao núcleo artístico da educação no desenvolvimento de seu projeto, o filósofo francês argumenta que a falência das Luzes deveria ser tomada na atualidade como um luto a ser vivido, como um sinal do declínio do humanismo no qual se pautou. Esse luto faria parte desse trabalho de perlaboração da modernidade, como sua rescrita. Afinal, nos dias de hoje, como sugere lyotard, em uma entrevista concedida a 
Kechikian (1993), o saber não seria mais um meio de emancipação: é um luxo que homem se oferece a si próprio, um produto no meio de uma diversificação crescente e de uma multiplicação aleatória da vida, que representaria a imagem que o cosmos produz de si mesmos, não pertencendo ao homem. Ao homem, caberia apenas complexificar esse produto e compreender essa imagem à luz do pensamento, não por destinação, mas pelo maior dos acasos, fazendo o que lhe caberia fazer: a complexificação de nossos conhecimentos. Como o filósofo francês afirma, na entrevista a Kechikian (1993, p. 50), desse ponto de vista, a finalidade que atribuiria à educação seria de "tornar as pessoas mais sensíveis às diferenças, de fazê-las sair do pensamento massificante", sendo necessário formar o espírito para a complexidade na contemporaneidade. Na entrevista, ele argumenta também que, se tivesse que pensar num sistema educativo para a realização dessa finalidade, o formularia à luz de uma política da resistência, isto é, a uma resistência ao pior, "quer dizer manter um número de idéias a favor e contra tudo", mesmo que elas não possam ser aplicadas de imediato. Ele defende, em síntese, uma adaptação ao complexo, refreando aquilo que tende ao maciço e ao simplista e que, na perspectiva de sua rescrita da modernidade, se converteu a pós-modernidade. Desse modo, o filósofo francês problematiza qualquer pedagogia que se pretenda lluminista, com exceção daquela que elabora o trabalho de luto ou de perlaboração do humanismo nos termos da rescrita da modernidade, perspectivando politicamente uma educação capaz de resistir ao totalitarismo e de tornar as pessoas sensíveis às diferenças.

Assim compreendida, a alternativa apresentada pelo filósofo francês para pensar a educação, na contemporaneidade, não teria por pressuposto uma filosofia antropológica nem buscaria um sentido humanista para a formação humana, nos termos em que se teria constituído uma tradição, inclusive em Filosofia da Educação. Afinal, Lyotard (1997) não pretende restaurar o humanismo, mas ao recuperar a dimensão artística da formação humana, caracterizá-la como uma arte cuja única preocupação seja a de tornar o homem inumano, como fizeram alguns movimentos vanguardistas na arte e alguns filósofos. Isso significa considerar o inumano, por um lado, como decorrência do constrangimento provocado pelo desenvolvimento do sistema socioeconômico atual, pretensamente humano ou humanista; por outro, como algo que habita o humano e sempre o acompanhou. Diz Lyotard (1997):

A inumanidade do sistema em curso de consolidação, sob o nome de desenvolvimento (entre outros), não deve ser confundida com aquela, infinitivamente mais secreta, de que a alma é refém. Acreditar, como aconteceu comigo, que a primeira possa substituir a última, dar-lhe expressão, é cair no engano. A conseqüência maior do sistema é fazer esquecer tudo o que the escapa. Mas a angústia, o estado de espírito assombrado por um hóspede familiar e desconhecido que o agita, fá-lo delirar, mas também pensar - se pretendemos excluí-lo, se não the damos saída, agravamo-lo. 0 mal-estar aumenta com esta civilização, a exclusão com a informação. (p.10)

Se o problema do inumano é compreendido assim, em contrapartida, o que poderia ser chamado de humano no homem? A educação humanista tentou responder a essa questão, segundo ele, de dois modos. De um modo, dizendo que o homem se tornaria humano, se livrando de sua natureza próxima aos animais, com a qual nasce, e da miséria de sua infância, adquirindo uma segunda natureza, a da cultura, que o tornaria apto para "partilhar da vida comum, da consciência e da razão adultas" (Lyotard, 1997, p.11). Restaria saber se aquela natureza e infância não deixariam vestígios nessa dialética pressuposta pela educação humanista. Segundo o autor, esses vestígios poderiam ser encontrados na contínua luta dos adultos para assegurar a sua conformidade com as instituições e para aprimorá-las no sentido 
de um melhor partilhamento da vida comum, porém o poder de criticá-las, a dor de suportálas e a tentação de se lhes escapar seriam sintomas, e não somente singulares, de restos de uma indeterminação, de uma infância persistente, mesmo na idade adulta. De outro modo, a educação humanista também admitiu a criança, o seu desprovimento de fala, a inabilidade de calcular os seus benefícios e a hesitação em decidir sobre seu interesse, como eminentemente humanos, porque essa sua aflição seria uma promessa de possíveis. Afinal, segundo Lyotard (1997), o seu atraso inicial em relação à humanidade a torna refém da comunidade adulta, em virtude de sofrer de uma falta que a chama para se tornar mais humana. Mesmo quando supre essa falta, dotando-se dos meios de saber e de fazer saber, de agir e de fazer agir, interiorizando os interesses e os valores da civilização, o adulto ainda aspira à plena humanidade, à realização do espírito como consciência, conhecimento e vontade. Assim, a condição do homem seria a de restar sempre a da possibilidade de se libertar da "selvageria obscura de sua infância cumprindo essa promessa" (p. 11).

Nesses dois modos da educação humanista, não existiria senão, para o filósofo francês, uma diferença de acento, que uma dialética ou hermenêutica tentariam reconciliar em nome do humanismo. Alguns dos filósofos contemporâneos buscariam essa reconciliação da formação humana, recordando a falta do que é próprio do homem ou a sua transcendência para a completude. Contudo, Lyotard (1997) diz que não lhe agrada nem a pressa com que eles fazem isso nem essa reconciliação, buscando aquilo que é inconciliável e invertendo os propósitos do humanismo a fim de nele revelar o inumano. Isso porque ele considera o seguinte:

É preciso antes de mais nada recordar que se o título de humano pode e deve caminhar entre a indeterminação nativa e a razão instituída ou a instituir-se, também o pode e deve o inumano. Toda educação é inumana visto que não funciona sem contrariedades e terror, e refiro-me a menos controlada, menos pedagógica, aquela que Freud chama de castradora e que o faz dizer, a propósito da 'boa maneira' de educar as crianças, que de qualquer forma será má (nisto próxima a melancolia kantiana). E inversamente, tudo o que é instituído pode, por vezes, deixar transparecer o infortúnio e a indeterminação é de tal maneira ameaçador que o espírito razoável não pode deixar de temer, justificadamente, uma força inumana de desregulação. (p. 12)

0 filósofo francês justifica esse acento no inumano que desafia a Filosofia da Educação, na atualidade, em razão da alteração profunda da natureza do próprio sistema, tal como prenunciou ao conceber a condição pós-moderna e detalhou ao substituir tal expressão por rescrita da modernidade. Em tais diagnósticos, ele interpreta o desenvolvimento do sistema como uma "ideologia do tempo presente". Para Lyotard (1997, p. 14), tal ideologia realizaria o essencial da metafísica, que tem sido muito mais um pensamento de forças do que um pensamento de sujeito. 0 que impressiona nessa "metafísica do desenvolvimento" seria o fato de que ela não precisa de nenhuma finalidade, apenas se aceleraria e estenderia segundo a sua própria dinâmica interna, sem pressupor qualquer emancipação ou liberdade, necessitando apenas de um "acaso cosmológico". Embora não tenha um fim, o desenvolvimento do sistema tem um limite, a explosão prevista do sol, que o desafia objetivamente, porque não está ao seu alcance transpô-la, comprometendo todos os campos de pesquisa e de sua aplicação, nos países ditos desenvolvidos, e subordinando o interesse dos seres humanos ao da sobrevivência da complexidade. Diante da esperança de uma alternativa decisiva ao sistema e da política revolucionária se encontrar sem emprego na atualidade, as questões levantadas pelo filósofo francês são as seguintes: que mais restaria de político que não seja a resistência a esse inumano? Para opor essa resistência, o que mais restaria além da dívida que toda a alma contraiu com a indeterminação miserável de 
sua origem, da qual não cessa de nascer, ou seja, com o outro inumano? Para Lyotard (1997), essas questões tocam na dívida para com a infância, que ainda não foi saldada, mas que bastaria, para tanto, não a esquecer para resistir e, talvez, para não ser injusto. A essa tarefa, a escrita, a arte e a filosofia poderiam aventurar-se a prestar testemunho.

A obediência a essa dívida para com a infância e essa resistência ao seu esquecimento implicaria numa valorização de si mesmos. Para lyotard (1993), uma valorização de si mesmo, do que fomos e somos como acontecimento no mundo, poderia ser produzido em nossa experiência singular e histórica, por intermédio de um ato filosófico, que nos colocaria diante do começo que significou a nossa infância, as misturas físicas e simbólicas com os nossos pais, reconhecendo aí os rastros e os caminhos entre abertos que ela nos deixou. Diferentemente de um corpo de saber, de saber-fazer e de saber sentir que se encontraria em potência em cada um de nós, esse ato filosófico só existiria como ato e não como uma potência a ser desdobrada, desenvolvida ou desprendida por meio da educação. Ele não se pautaria na idéia de que o espírito não seria dado aos homens como preciso, devendo-se reformá-lo. Ao contrário, o encontro desse ato com a infância, até então considerada como o monstro dos filósofos, tornar-se-ia agora seu cúmplice, ensinando-o a perceber que, embora o espírito não fosse dado, seria possível. 0 filosofar seria uma atividade que segue um curso no mundo e que não implica numa relação com um saber administrado pelos educadores aos educandos, mas num processo de identificação e desvencilhamento em que ambos se re-formam, como autodidatas, que nunca alcançam uma identidade adequada, colocando-os sempre no difícil trabalho de recomeçar, conforme desenvolvido por Pagni (2005).

Mediante o compromisso com esse trabalho de recomeçar, necessário ao filosofar, é possível dizer que ele se nutre por uma busca do sentimento (do) sublime nos termos expostos em seu projeto filosófico. Isso auxilia a pensar com esse projeto o modo pelo qual tal problemática estética estaria presente no trabalho educativo, explicitando a sua dimensão artística e o modo como tal problema se ligaria ao sentido de uma política de resistência ao existente nos termos indicados pelo filósofo francês. Em tais relações, a Filosofia da Educação poderia auxiliar a pensar em uma experiência formativa em que as pessoas se tornassem mais sensíveis à diferença e abertas a pensar a complexidade do mundo atual, contrapondo-se a simplificação e a massificação onipresentes em nossa cultura. Elas poderiam resistir ao inumano e encontrar no refúgio da infância do pensamento a possibilidade de criar novos modos de agir e de pensar no mundo, por meio dessas sinalizações de sentidos para a educação, na contemporaneidade, abertos pela interpretação do projeto lyotardiano antecedente. Para tanto, a Filosofia da Educação deveria se colocar questões específicas que lhe fossem desafiadoras, desde a atividade pedagógica, para a qual o projeto lyotardiano não se refere diretamente, mas faz indicações para que o olhar de pesquisadores desse campo e educadores se volte. Esse olhar pode se voltar, assim, ao problema do sublime e ao recurso à explicitação de diferendos constitutivo dessa prática, de modo a pensarem nas questões que desafiam a sua arte e a sua própria experiência formativa, justamente por os afligirem, no presente, e por não terem sido ainda pensadas com cuidado pela tradição.

Não é possível depreender da interpretação do projeto lyotardiano, exposta anteriormente, nenhum tipo de Filosofia da Educação com base em uma filosofia antropológica, mas apenas focalizar questões que a desafiassem, na atualidade, circunscritas às relações entre a estética e a política, abordadas pela sua filosofia. Se a rescrita da modernidade desafia teoricamente a Filosofia da Educação a abordar o problema do inumano e da infância, excluídos da tradição pedagógica humanista, a problemática do sublime, enunciada em seu projeto, auxilia os pesquisadores desse campo e os educadores em geral a compreenderem a di- 
mensão artística do trabalho pedagógico. A explicitação de tal dimensão, por meio da explicitação dos diferendos que a compreendem, pode fazer dele não um fenômeno a ser conhecido cientificamente e uma prática a ser empreendida tecnologicamente, mas uma arte em que o pensar por parte de seus agentes está em xeque constantemente, em função do mundo em que vivem e da instabilidade de suas próprias existências. Nesse sentido, o problema do sublime que leva os seus agentes a pensarem teoricamente a sua ação no mundo, os seus sentidos e a si mesmos, dá a eles o que pensar, desafiando a Filosofia da Educação para se tornar um compromisso com esse filosofar em tais circunstâncias.

Em busca de um sublime que dê o que pensar aos professores e alunos, a Filosofia da Educação vê-se instigada a produzir uma prática que leve ao filosofar aqueles agentes do ensino, mediante questões que despertem um sentimento de angústia próximo ao da criação artística: um sentimento que consiste na eventualidade de nada ocorrer, no instante, na aula, um ócio necessário ao pensamento criativo. Analogamente ao pintor ou ao escritor que, diante da tela ou da página em branco, se vê em compasso de espera de um acontecimento a partir do qual emerge a sua pintura e a sua escritura e no qual encontra o sentimento de existência e de prazer, mediante a sua criação, a aula poderia ser um tempo-espaço aberto a acontecimentos: não fosse a sua excessiva regulamentação e disciplinarização. Tal acontecimento poderia provocar espanto e admiração, nos partícipes dessa aula, mediante pensamento de suas relações com o mundo e com si mesmo, com suas experiências singulares e históricas, caso eles não estivessem imbuídos de defesas uns contra os outros, de uma moralidade e de uma adaptação ao existente, provenientes da tradição cultural na qual estão inseridos e do instituído.

Se as teorias pedagógicas não consideram o que o sentimento sublime propicia ao pensar, em práticas como o ensino, foi porque nelas predominou o pressuposto de certo ideal humanista e unidade da linguagem, característica, respectivamente, da cultura e da pragmática do saber científico na pós-modernidade. Caberia a uma Filosofia da Educação inspirada no projeto lyotardiano resistir a essa suposta pósmodernidade, pensando justamente o que tais teorias desconsideraram e o que ainda poderia ser desafiador à prática do ensino e à aprendizagem. Em relação aos agentes desse ensino e dessa aprendizagem, tal Filosofia da Educação poderia torná-los mais atentos à complexidade e sensíveis às diferenças, de modo a elaborá-las e de pensá-las, no sentido da resistência ao existente e do comprometimento com essa tarefa ética e política. Mediante essa atitude, talvez, se evitasse o pensamento totalizante proveniente daquelas teorias pedagógicas que, nas práticas formativas ou comunicativas que compreendem o ensino, assumem um caráter doutrinário ou meramente prescritivo, resistindo às formas de socialização e comunicação que, respectivamente, silenciaram o inumano em nome do humano e o dissentimento em prol do consenso. Isso não significa abandonar a tradição cultural e o saber científico que lhes são constitutivas, mas lembrar a essas práticas o que esqueceram, desde a modernidade; reescrevê-las, tendo em vista o que, respectivamente, deformaram em nome da formação humana e da heterogeneidade da linguagem ou das razões, que subordinaram a unidade do gênero cognitivo ou de uma razão cogitante ou logocêntrica.

Para além de suspeitar da tradição em que se inscreveram e da linguagem universal que pressupôs uma comunicação sem ruídos desde a modernidade, esse trabalho de constante recomeçar a pensar na educação, pensando o próprio pensamento e dar voz ao silenciado na infância, auxilia a dissentir sobre o convencionado no presente. Nesses termos, ele tem o sentido de criar problemas filosóficos não convencionais nessas práticas e testemunhar o infortúnio do próprio silêncio que aflige o pensamento, antes de se tornar linguagem e ser comunicado. Por um trabalho de escuta analítica desse silêncio e do fazer aflorar o sentimen- 
to do sublime, mediante os acontecimentos, nessas práticas, procura partilhar o sensível e promover em seus agentes o compromisso com um outro da comunicação e de si mesmo. Assim, o testemunho que pode ser prestado nessa forma de filosofar na educação é o daquele que desafia a toda comunicação por ela compreendida, porque se refere ao incomunicável.

Os desafios lyotardianos implicam em questões que decorrem não do assentimento dos alunos em relação às proposições enunciadas pelos seus mestres, mas do dissentimento suscitado no que se refere a essas proposições, ao que foi silenciado por elas e aos limites de sua enunciação, na comunicação estabelecida nesse contexto de ensino e de aprendizagem. $\mathrm{Na}$ inquietude desse dissentimento é que professor e aluno se deparam com o silêncio sobre o qual mobilizam seus pensamentos, insistentemente, às questões suscitadas em suas práticas e, mediante tais pensamentos, se modificam a si mesmos, tentando dar voz ao que foi silenciado. Embora esse silêncio não possa ser comunicado, questões como as das injustiças que cometem um contra o outro, nessa estrita relação de poder podem ser testemunhadas por professor e aluno, desde que tenham compromisso para com o outro da comunicação e o que habita a si mesmo, sendo capazes de falar sobre elas, explicitando os conflitos que regem experiências formativas incomuns, diferentes. Por meio desse compromisso em explicitar os diferendos que compreendem essa experiência deformativa, em que ao inumano é dado voz, e desse testemunho quase sempre hesitante por parte de professores e alunos, o sentimento sublime pode ser experienciado por eles, movendo seus pensamentos para os problemas que têm em comum, já que habitam o mundo e se relacionam com ele.

Mediante tais pensamentos, eles poderiam buscar sentidos fecundos para as suas existências no mundo, concorrendo para modificar aquelas pela transformação deste ou vice-versa. Ainda que tais sentidos não se reduzam ao sentido da existência, consentido pelo aluno às proposições do professor, eles podem propiciar encontros para que o autodidatismo de um e de outro se relacione, conforme não seus interesses, mas o decurso de suas experiências no mundo. Embora esse encontro não seja planejado, dado o caráter indeterminado da experiência formativa, ele pode ser persistentemente buscado, como um acontecimento a ser perspectivado, sem jamais ter-se a garantia prévia de sua efetivação. Porém, tal acontecimento não é semelhante à transmissão do saber científico nem à comunicação pelo professor de uma habilidade de pesquisar o que não se sabe ao aluno, que continuam sendo necessárias ao ensino, mas assemelha-se a uma experiência estética que se apresenta antes da razão, da multiplicidade compreendida por ela, responsável pela desordem pragmática anteriormente analisada.

Por isso, ele assombra o professor formado em uma cultura em que ele é quem sabe e quem comunica ao receptor aluno um saber ou uma habilidade, mas também pode admirálo tanto quanto ao aluno. Por intermédio desse assombramento, o professor pode encontrar no isolamento do gênero poético, por meio dos jogos de linguagem e pela explicitação dos diferendos, uma forma de dar voz ao incomunicável dessa comunicação, partilhar o sensível dessa relação, com o intuito de afetar os alunos: não para produzir uma empatia que se esgota em si mesma, mas para desafiá-los a pensar sobre o outro de si mesmos, o inumano ao qual deve resistir em face das coações do sistema, que são comuns a ambos. Sem que isso implicasse em buscar um consenso estabelecido para se livrar de tais coações ou da homogeneização dos desafios, desse modo, eles poderiam compartilhar com os seus alunos, uma sensibilidade comum, se não fosse a persistência por parte do professor em querer implicar a dialética ou a dialógica, na qual persiste a agonística.

Considerando essa agonística, os professores poderiam se apropriar das questões específicas depreendidas do projeto filosófico lyotardiano para buscar questões que desafiassem os alunos no âmbito da prática institucionalizada, fazendo filo- 
sofia da educação em seu sentido estrito de um filosofar interpelador sobre a sua própria prática, dos regimes discursivos e dos sentidos que a compreendem no presente. Se esse modo de fazer filosofia da educação for incapaz de desafiar os alunos a romperem o círculo social que se fecha sobre eles e compartilhar essa sensibilidade, na escola, em função de estarem totalmente enredados ao instituído, segundo Lyotard, outras Ágoras, àqueles que nutrissem certa sensibilidade ao diferenciado e estivessem desafiados a uma experiência com esse pensar, salvando a sua honra e resistindo à sua expropriação na contemporaneidade. Ainda que seja tardiamente, na vida adulta, a experiência com esse pensar poderia levar esses indivíduos ao reconhecimento de sua incompletude, da insatisfação que ela gera e que nos faz buscar a criação. Isso implicaria no compartilhamento de uma sensibilidade incomunicável e no reconhecimento de uma menoridade intelectual que, ao invés de gerar imobilização, levaria a uma atitude de resistência ao existente e de ruptura com ele, por meio da criação de outros modos de pensar e de agir sobre e no mundo.
Das indicações depreendidas da interpretação do projeto filosófico de Lyotard, desenvolvido após a revisão de algumas de suas posições sobre a pós-modernidade, para se pensar na atividade educativa, pode-se dizer que elas são fecundas para desafiar a filosofia da educação e os educadores, na atualidade, ao menos no que se refere aos aspectos destacados neste artigo. Se a maioria dos estudos circunscreveu à polêmica as posições de lyotard ou de um de seus protagonistas para depreender daí suas implicações para a educação, as indicações aqui reunidas são as de que recuperar esse projeto filosófico para pensar com ele questões educacionais mais do que posições teóricas asseguradas ou previamente estabelecidas, para além da pós-modernidade. Espera-se que, dessa forma, outras pesquisas em Filosofia da Educação possam ser desenvolvidas e a reflexão dos educadores possa ser desafiada a partir dessas indicações, antes do que deixar-se levar por uma polêmica, que parece ter perdido há muito o seu tom desafiador, ou pela adesão a uma doutrina supostamente nova, posterior à modernidade, dita pós-moderna.

\section{Referências bibliográficas}

ERIBON, D. Michel Foucault e seus contemporâneos. Rio de Janeiro: Jorge Zahar, 1996. 244p.

GHIRALDELLI JÚNIOR, P. A filosofia contemporânea e a formação do professor: o "aufklärer moderno" e o "liberal ironista". Perspectiva: Revista do Centro de Ciências da Educação. Florianópolis, ano 14, n. 25, p. 95-110, jan./jun.1996.

Para ler Richard Rorty e sua Filosofia da Educação. Filosofia, sociedade e educação. Marília, ano I, n. 1, p. 09-30, 1997.

Filosofia da Educação. Rio de Janeiro: DP\&A, 2001. 108p. (0 que é preciso saber sobre...)

GONÇALVES, M. A. S. Teoria da Ação Comunicativa de Habermas: possibilidade de uma ação educativa de cunho interdisciplinar na escola. Educação \& Sociedade. Campinas, ano XX, n. 66, p. 125-140, abr. 1999.

GÖERGEN, P. L. A crítica da modernidade e a educação. Pro-posições. Campinas, v.7, n. 2[20], p. 05-28, jul. 1996.

Pós-modernidade, ética e educação. São Paulo: Autores Associados, 2001. 95p. [Col. Polêmica de nosso tempo].

HABERMAS, J. 0 discurso filosófico da modernidade. Lisboa: Publicações Dom Quixote, 1990. 350p.

Modernidade: um projeto inacabado. In: ARANTES, O. B. F.; ARANTES, P. E. (Orgs.). Um ponto cego no projeto no projeto moderno de Jürgen Habermas. São Paulo: Brasiliense, 1992, p. 99-124.

HUTCHEON, L. A incredulidade a respeito das metanarrativas: articulando pós-modernismo e feminismo. Labrys: estudos feministas. Brasilia, n. 1-2, jul./dez. 2002. Disponível em: <http://www.unb.br/ih/his/gefem/labrys1_2/linda1.html>. Acesso em: 12 de maio de 2006. 
KECHIKIAN, A. Os filósofos e a educação. Lisboa: Edições Colibri, 1993, p. 47-53.

LYOTARD, J. F. 0 pós-moderno explicado às crianças: correspondência 1982-1985. 2. ed. Lisboa: Publicações Dom Quixote, 1993. 0 inumano: considerações sobre 0 tempo. 2. ed. Lisboa: Editorial Estampa, 1997, 202p. La diferencia. Barcelona: Gedisa Editorial, 1999 [terceira reimpressão]. 224p. A condição pós-moderna. 6. ed. Rio de Janeiro: José Olympio, 2000 [1997], 132p.

MARQUES, M. 0. Os paradigmas da educação. Revista Brasileira de Estudos Pedagógicos. Brasília, v. 73, n. 175, p. 347-385, set./dez. 1992.

MARKERT, W. Ciência da Educação: entre modernidade e modernismo. Revista Brasileira de Estudos Pedagógicos. Brasília, v. 67, n. 5, p. 306-319, maio/ago. 1986.

MEDEIROS, M. F. Eixos emergentes na proposta habermasiana e a possibilidade da ação pedagógica crítica e reflexiva. Educação e Filosofia. Uberlância, v. 8, n. 15, p. 49-66, jan./jun. 1994.

MORAES, M. C. M. Os "pós-ismos" e outras querelas ideológicas. Perspectiva: Revista do Centro de Ciências da Educação. Florianópolis, ano 14, n. 25, p. 45-60, jan./jun.1996.

0 renovado conservadorismo da agenda pós-moderna. Cadernos de Pesquisa. São Paulo: Fundação Carlos Chagas, v. 34, n. 132, p.337-357, maio/ago. 2004. Disponível em: <http://www.scielo.br/pdf/cp/v34n122/22508.pdf. >. Acesso em: 22 de maio de 2006.

PAGNI, P. A. Os limites e as discretas esperanças do ensino de Filosofia: a questão da educação dos educadores aos temas relativos ao amor e à infância no pensamento contemporâneo. In: GALLO, S.; DANELON, M.; CORNELLI, G. (Orgs.). Ensino de Filosofia: teoria e prática. Ijuí: Editora UNIJUÍ, 2004, p. 217-265.

. 0 filosofar na arte de educar entre o corpo e a infância: considerações a partir de Adorno e Lyotard. Childhood and Philosophy. Rio de Janeiro, v. 1, n.1, 2005. Disponível em:<http://www.filoeduc.org/childphilo/n1/Artigo\%20\%20Pedro\%20Pagni.htm>. Acesso em: 19 de maio de 2006.

RORTY, R. Habermas e Lyotard: quanto à pós-modernidade. In: v. 2. Rio de Janeiro: Resume Dumará, 1999, p. 221-236.

Ensaios sobre Heidegger e outros: escritos filosóficos. Cosmopolitismo sem emancipação: uma resposta a Jean-François Lyotard. In: verdade: escritos filosóficos. V. 1. 2. ed. Rio de Janeiro: Resume Dumará, 2002, p. 281-294.

SILVA, T. T. da. 0 adeus à metanarrativas educacionais. In: 0 sujeito da educação: estudos foucaultianos. 2. ed. Petrópolis: Vozes, 1994, p. 247-258.

. 0 projeto educacional moderno: identidade terminal? In: VEIGA-NETO, A. J. (Org.). Crítica pós-estruturalista e educação. Porto Alegre: Sulina, 1995, p. 245-260.

VEIGA-NETO, A. J. Michel Foucault e Educação: há algo de novo sob o sol? In: Porto Alegre: Sulina, 1995, p. 9-56. Crítica pós-estruturalista e educação.

Recebido em 27.06.06 Aceito em 03.10.06

Pedro Angelo Pagni é professor assistente doutor do Departamento de Administração e Supervisão Escolar da FFC/UNESP, Campus de Marília. 